\title{
Biodegradable esophageal stents in benign and malignant strictures - a single center experience
}

Authors

Institution
Dimitrios E. Sigounas, Sandeep Siddhi, John N. Plevris

Centre for Liver \& Digestive Disorders, The Royal Infirmary, University of Edinburgh, Edinburgh, Scotland, UK submitted

24. November 2015

accepted after revision

7. March 2016

\section{Bibliography}

DOI http://dx.doi.org/

10.1055/s-0042-105433

Published online: 15.4.2016

Endoscopy International Open

2016; 04: E618-E623

(c) Georg Thieme Verlag KC

Stuttgart · New York

E-ISSN 2196-9736

\section{Corresponding author}

\section{Professor John N. Plevris}

Centre for Liver \& Digestive Disorders

The Royal Infirmary

University of Edinburgh

51 Little France Crescent

Edinburgh EH16 4SA

Scotland, UK

J.Plevris@ed.ac.uk

\section{License terms}

()(1) $\Theta \circledast$
Background and study aims: Biodegradable (BD) esophageal stents were recently developed mainly for refractory benign strictures, but experience and available literature are limited.

Patients and methods: This was a retrospective observational study. All patients who had BD stents inserted due to refractory benign esophageal strictures or malignant strictures, or were awaiting radical radiotherapy/chemotherapy or neo-adjuvant therapy and esophagectomy between March 2011 and July 2015 were included. Results: Stent placement was successful in all patients. Ten patients with benign strictures (3 male, median age 80.5 years, IQR: $68.75-89.5$ ) were followed-up for a median of 171.5 weeks (IQR: 24-177.25). The interval between dilatations prior to the first BD stent placement (median: 34.25 days, IQR: 23.06-48.29) was significantly shorter than the interval between the first BD stent placement and the first intervention required (median: 149.5 days, IQR: 94.25-209.5)

\section{Introduction}

$\nabla$

Esophageal strictures are common, though the use of proton pump inhibitors has greatly reduced the incidence of benign peptic strictures $[1,2]$. Strictures can occur secondary to gastroesophageal reflux disease (GORD) and caustic ingestion and after esophageal surgery or radiotherapy [3]. Management of esophageal strictures is a clinical challenge. Currently the practice in most units is recurrent dilatation for benign peptic strictures with balloon or bougies. Even though $80 \%$ to $90 \%$ of patients will initially respond to dilatation, a majority of them will need more than 1 session and fewer than $10 \%$ will experience refractory or recurrent strictures, with repeated dilatation having only minimal effect. Multiple dilatation sessions expose the patient to cumulative risks associated with the procedures and carry a small, nevertheless significant risk of perforation and and this difference was statistically significant $(P=0.012)$. Ten patients with esophageal cancer ( 8 male, median age: 69 years, IQR: $59.25-80.75$ ) were included and they were followed up for a median of 36 weeks (IQR: 26 -58). Only 1 completed radical radiotherapy successfully, but developed refractory post-radiotherapy stricture. No one proceeded to esophagectomy and $50 \%$ required a self-expanding metal stent (SEMS) at a median of 134 days (IQR: 100-263) following stent placement.

Conclusions: BD stents were successfully deployed in both benign and malignant strictures. They offered a prolonged dilatation-free interval in benign strictures, yet in the majority of patients, strictures recurred. In malignant strictures, stent patency was similar to that of benign strictures, which suggests a potential value in ensuring adequate oral intake during oncologic therapy. In our cohort, however, use of stents did not contribute to improved outcome.

even death [3]. Other therapeutic modalities, such as intralesional injection of steroids, have been assessed with encouraging results [4], however, multiple sessions typically are needed and long strictures are difficult to treat. In addition to these, the optimal injection technique as well as the frequency and dose of steroids to be used are yet to be established [5]. Removable plastic (SEPS) or fully covered metal self-expanding stents (FCSEMS) have also been tried, but initial positive results were not replicated [6,7] and a recent meta-analysis reported significant migration rates and mediocre success rates overall [8].

Esophageal malignancies are usually associated with stricture disease and self-expanding metal stent (SEMS) placement is a well-established palliative modality. However, in patients who are candidates for neoadjuvant chemo-radiotherapy (CRT) prior to surgery or radical radiotherapy, insertion of uncovered or partially covered metal 
stents is associated with a number of problems such as tumor ingrowth, stent displacement, inability to remove and difficulties posed during surgery and radiotherapy planning [9-12]. Therefore, FCSEMS as well as SEPS have been used, in view of their ability to be removed when needed. Results were inconsistent, but generally suboptimal, with most studies showing significant stent migration rates [13].

There is a need to develop a new strategy to improve outcomes for both benign and malignant indications. Stents made of biodegradable material were first developed and tried in 1997 [14], but it was only in 2008 that a new biodegradable (BD) stent, the SX Ella BD Stent (Ella- CS, Hradec Kralove, Czech Republic), was developed and became available commercially for clinical use. Those stents biodegrade after 11 to 12 weeks, thus making them appealing alternatives for both benign esophageal strictures and malignant ones, as a bridge to more radical interventions [15]. The aim of this study was to retrospectively evaluate the clinical effectiveness and safety of the SX Ella BD stent in benign and malignant strictures.

\section{Patients and methods}

$\nabla$

This was a retrospective, single-center study, in a university hospital and tertiary referral center in Scotland, UK. The hospital's electronic records database, as well as the endoscopy reports electronic database, were reviewed for all patients who had the stent inserted from March 2011 until July 2015. We started to use the biodegradable stents in 2011 for benign strictures. In those cases, malignancy was excluded after multiple biopsies. The use of the stents was later extended to malignant strictures.

\section{Ethics}

This study was conducted in accordance with UK research ethics guidelines. After review by the local ethics committee, further specific ethical review and approval were not required, as the study was considered a retrospective clinical audit work, using data already obtained as a part of regular patient care.

\section{Patient cohort for stent insertion}

All patients who had the stent inserted from March 2011 to July 2015 were included in this retrospective study. The end of follow-up period for each patient was July 2015 or time of death. Patients were selected for insertion of the BD stent on an individual basis after discussing the risks and benefits and obtaining an informed consent. Dysphagia was the main symptom. In our series we included a number of recurring strictures ( $>3$ consecutive dilatations) but in such cases, patients were keen to consider alternative options rather than continue with further dilatations and a number of refractory strictures when a lumen of $15 \mathrm{~mm}$ after at least 5 dilatations could not be maintained. All the cases represent real-life clinical data. Because this was not a strict protocol-driven prospective study, patient preferences as well as logistic restrictions occasionally influenced the timing and number of procedures. Patients with benign esophageal strictures were initially selected, as they were considered to represent the group who would mainly benefit from this new modality and for whom most evidence was available. All patients in the benign group had malignancy excluded on multiple biopsies.

When more experience was gained locally and after reports of its use in malignant strictures became available, this modality was offered to a select group of patients with malignant strictures fol- lowing discussion at the regional multidisciplinary upper gastrointestinal cancer case conference and with the patients' agreement to consider this interim treatment option. In such cases the decision to insert a BD-stent was made to give the opportunity to assess the initial response to chemotherapy or radiotherapy before the final management decision. Such patients were fit but borderline candidates for radical therapies due to disease staging and in most cases were of a younger age group. It is of note that the use of BD-Stent is licensed only for benign strictures and its use in the setting of malignancy is "off-label."

\section{The stent}

The biodegradable stent available as the SX Ella BD Stent, EllaCS (Hradec Kralove, Czech Republic) is made of woven polydioxanone monofilament and available in lengths from $60 \mathrm{~mm}$ to $135 \mathrm{~mm}$. It is radiolucent but has radiopaque markers at both ends and in the middle. The material degrades by hydrolysis, which is accelerated by low $\mathrm{pH}$. The mechanical strength lasts for about 3 weeks and it begins to disintegrate in 11 to 12 weeks. Pre-dilation of the stricture just prior to insertion of the stent is recommended. The stent needs to be assembled and loaded onto the delivery system prior to insertion. It has a distal release mechanism.

All procedures were undertaken by endoscopists with experience in esophageal stenting and all procedures took place at the radiology suite, under fluoroscopic guidance. Standard doses of sedation and analgesia (midazolam and fentanyl) were used along with topical anesthesia. Patients were in the left lateral position. As a rule, all patients had their stricture dilated to 11 to $12 \mathrm{~mm}$ with a controlled radial expansion (CRE) balloon or Savary-Gilliard dilator prior to stent insertion. This was per the recommendation from the manufacturer. In order to facilitate accurate stent placement, $1 \mathrm{~mL}$ to $2 \mathrm{~mL}$ of contrast was injected submucosally, using a sclerotherapy needle just above the stricture, and under fluoroscopic guidance, the point of injection was aligned to the markers on the proximal end of the stent. Correct positioning was checked endoscopically.

\section{Statistical analysis}

Statistical analysis was conducted using SPSS 21.0 (IBM corp., Version 21.0, Armonk, NY, USA). Data are presented as frequencies for categorical variables and as median and interquartile range (IQR) for continuous variables. The mean time between dilatations, in days, was calculated as the time interval between the first dilatation and the first BD stent placement/number of dilatation prior to BD placement. This was compared to the time interval between the BD stent insertion and the first intervention (dilatation or further stent placement) required after the first $B D$ stent, using Wilcoxon signed rank test. A $P$ value less than 0.05 was considered as statistically significant.

\section{Results}

\section{$\nabla$}

\section{Benign strictures}

\section{Patient characteristics and outcomes}

A total of 17 stents were inserted in 10 patients with benign strictures. There were 3 males and 7 females ranging in age from 54 years to 101 years (median: 80.5 years, IQR: 68.75-89.5). The median follow-up period was 171.5 weeks (IQR: 24-177.25). Eight of the patients had peptic strictures, while 1 had a benign stricture following radical radiotherapy for esophageal squamous 
Table 1 Benign strictures. Patient characteristics and follow up including the number of pre- and post BD stent placement dilatations, the mean interval between dilatation prior to BD stent placement, the mean interval for repeat intervention following BD stent placement, number of BD stents used in each patient and overall clinical course of each patient.

\begin{tabular}{|c|c|c|c|c|c|c|c|c|c|}
\hline Patient & Age & Gender & $\begin{array}{l}\text { Stricture } \\
\text { cause }\end{array}$ & $\begin{array}{l}\text { pre-BD stent } \\
\text { dilatations }\end{array}$ & $\begin{array}{l}\text { Post-BD } \\
\text { stent dilata- } \\
\text { tions }\end{array}$ & $\begin{array}{l}\text { Mean interval } \\
\text { (days) between } \\
\text { dilatations prior } \\
\text { to BD stent }\end{array}$ & $\begin{array}{l}\text { Interval be- } \\
\text { tween } B D \text { stent } \\
\text { and } 1^{\text {st }} \text { inter- } \\
\text { vention }\end{array}$ & $\begin{array}{l}\text { Total } \\
\text { number } \\
\text { of BD } \\
\text { stents }\end{array}$ & $\begin{array}{l}\text { Follow-up after } \\
1^{\text {st }} \mathrm{BD} \text { stent }\end{array}$ \\
\hline 1 & 71 & Female & Peptic & 3 & 4 & 67 & 190 & 2 & $\begin{array}{l}2^{\text {nd }} \mathrm{BD} \text { and SEMS } \\
\text { and dilatations }\end{array}$ \\
\hline 2 & 91 & Female & Peptic & 12 & 0 & 36 & N/A & 1 & $\begin{array}{l}\text { No further inter- } \\
\text { vention-deceased }\end{array}$ \\
\hline 3 & 54 & Male & Peptic & 8 & 7 & 33 & 244 & 2 & $\begin{array}{l}2^{\text {nd }} \mathrm{BD} \text { stent and } \\
\text { dilatations }\end{array}$ \\
\hline 4 & 101 & Female & Peptic & 7 & 5 & 45 & 216 & 2 & $\begin{array}{l}2^{\text {nd }} \mathrm{BD} \text { stent and } \\
\text { dilatations }\end{array}$ \\
\hline 5 & 72 & Female & Peptic & 4 & 4 & 58 & 89 & 2 & $\begin{array}{l}2^{\text {nd }} \mathrm{BD} \text { and SEMS } \\
\text { and dilatations }\end{array}$ \\
\hline 6 & 81 & Male & Peptic & 3 & 35 & 12 & 60 & 1 & Repeat dilatations \\
\hline 7 & 80 & Female & $\begin{array}{l}\text { Post-radio- } \\
\text { therapy }\end{array}$ & 8 & 7 & 21 & 169 & 3 & $\begin{array}{l}2 \text { more BD stents } \\
\text { and dilatations }\end{array}$ \\
\hline 8 & 85 & Female & Peptic & 3 & 3 & 36 & 110 & 2 & $\begin{array}{l}\text { Repeat dilatations- } \\
\text { Deceased- }\end{array}$ \\
\hline 9 & 89 & Female & Peptic & 6 & 1 & 24 & 130 & 1 & Repeat dilatation \\
\hline 10 & 62 & Male & $\begin{array}{l}\text { post-esopha- } \\
\text { gectomy }\end{array}$ & 4 & 0 & 24 & N/A & 1 & $\begin{array}{l}\text { No further inter- } \\
\text { vention-Deceased }\end{array}$ \\
\hline
\end{tabular}

BD, biodegradable; N/A, non-applicable; SEMS, self-expanding metal stent.

carcinoma and another had anastomotic strictures, following esophagectomy for esophageal cancer. The length of the strictures ranged from $0.5 \mathrm{~cm}$ to $8 \mathrm{~cm}$ (median: $4 \mathrm{~cm}$ ). Five patients had 2 BD stents each inserted over the course of the study and 1 patient had 3 stents. The remaining 4 patients had a single BD stent placed. Of 10 patients, 7 were still alive at the end of follow-up.Two died at 188 and 65 days after stent placement respectively, for reasons not related to the procedure, without having any further intervention performed in the meantime. An 85 -year-old patient died 1 year after BD stent placement and had required 3 dilatations and an additional BD stent following that. The indications for stent insertion, number of BD stents, and need for further interventions and final outcome are indicated in $\bullet$ Table 1.

All benign strictures were dilated using a CRE balloon at the time of stent insertion, with the exception of a single patient in whom a Savary-Gilliard (SG) dilator was used. Stent insertion was technically successful in all cases.

There was 1 serious complication in a patient who was admitted with sepsis post-stent insertion, which was successfully treated. A few minor complications were also recorded. One patient had mild pain post-insertion and 2 food bolus obstructions a few weeks after stent insertion that were relieved endoscopically. In one of them the lumen was actually patent by the time the endoscopy was done.

Overall, all surviving patients required repeat procedures. Two of them were treated with metal stents due to recurrent dysphagia despite repeat BD stent placement. They remained symptomatic however, and required further dilatations, even though at less frequent intervals.

\section{Effect of BD stent placement in the need for subsequent interventions}

Two of the 10 patients who received BD stents for benign strictures died without receiving further treatment following the procedure, as mentioned above. Among the remaining 8 patients, the interval between dilatations prior to the first BD stent placement varied between 12 days and 67 days (median: 34.25, IQR: 23.06 - 48.29). The interval between the first BD stent placement and the first intervention required (further $\mathrm{BD} /$ metal stent placement or dilatation) ranged between 60 days and 244 days (median: 149.5, IQR: 94.25-209.5). The difference between those 2 intervals was statistically significant $(P=0.012)$. The 6 patients who required more than one stent had equally prolonged periods without intervention (median interval of first intervention after the placement of the second BD stent: 199.5 days, IQR: 118.5330.25)

\section{Malignant strictures}

Ten patients had $11 \mathrm{BD}$ stents inserted for malignant strictures. Median follow-up was 36 weeks (IQR: 26-58). Those patients were planned to have radical chemotherapy and/or radiotherapy with curative intent or alternatively to receive neoadjuvant treatment awaiting esophagectomy. None of them had previous dilatation or stenting. All but $1 \mathrm{had}$ dilatation to $10 \mathrm{~mm}$ to $11 \mathrm{~mm}$ at the time of stenting. The length of stricture varied between $2 \mathrm{~cm}$ and $9 \mathrm{~cm}$ (median: $6 \mathrm{~cm}$ ). Stents measuring $6 \mathrm{~cm}$ and $13.5 \mathrm{~cm}$ in length were inserted. Three patients experienced mild to moderate pain post-procedure, lasting for less than 48 hours. There was 1 case of food bolus obstruction a few weeks after insertion, which was secondary to tumor in-growth and required plasma coagulation (APC).

Five of 10 patients had metal stents inserted between 77 days and 308 days following BD stent placement (median: 134 days, IQR: 100-263). This was due to tumor progression. The median interval between BD stent placement and death or SEMS placement, previously termed "stent patency period" [16] was 204 days (IQR: 131.25 - 279.5). Despite treatment with chemotherapy and/or radiotherapy, no patient managed to proceed to esophagectomy except 1 patient who had an attempted esophagectomy, 
Table 2 Malignant strictures. Data regarding patient characteristics, BD stent patency duration, need for SEMS and survival

\begin{tabular}{|c|c|c|c|c|c|c|c|c|c|c|c|}
\hline $\begin{array}{l}\text { Pa- } \\
\text { tient }\end{array}$ & Age & $\begin{array}{l}\text { Gen- } \\
\text { der }\end{array}$ & $\begin{array}{l}\text { Tumor } \\
\text { location }\end{array}$ & Histology & Stage & Final treatment decision & $\begin{array}{l}\text { Need } \\
\text { for } \\
\text { SEMS }\end{array}$ & $\begin{array}{l}\text { BD stent } \\
\text { patency } \\
\text { duration } \\
\text { (days) }\end{array}$ & $\begin{array}{l}\text { Time } \\
\text { to } \\
\text { SEMS } \\
\text { (days) }\end{array}$ & Death & $\begin{array}{l}\text { Survival post- } \\
\text { BD stent } \\
\text { placement } \\
\text { (days) }\end{array}$ \\
\hline 1 & 47 & male & Lower & $\begin{array}{l}\text { Adenocar- } \\
\text { cinoma }\end{array}$ & T2N0M1 & $\begin{array}{l}\text { Palliative (metastasis } \\
\text { seen in PET scan) }\end{array}$ & yes & 134 & 134 & yes & 357 \\
\hline 2 & 68 & male & Lower & Squamous & T3N1M0 & $\begin{array}{l}\text { Neoadjuvant chemother- } \\
\text { apy-attempted esopha- } \\
\text { gectomy but found to be } \\
\text { unresectable then re- } \\
\text { ferred for radiotherapy } \\
\text { following BD }\end{array}$ & no & 189 & N/A & yes & 189 \\
\hline 3 & 80 & female & Lower & Squamous & T3NOMO & $\begin{array}{l}\text { Radical Rx-decision to } \\
\text { continue with palliation } \\
\text { following BD-stent inser- } \\
\text { tion }\end{array}$ & no & 690 & N/A & yes & 690 \\
\hline 4 & 60 & male & Lower & Squamous & $\begin{array}{l}\text { EUS:T4N2Mx } \\
\text { PET: T3N1M0 }\end{array}$ & $\begin{array}{l}\text { Chemotherapy with very } \\
\text { low success potential in } \\
\text { view of considering re- } \\
\text { section if disease re- } \\
\text { sponded, but disease } \\
\text { progressed }\end{array}$ & no & 239 & N/A & yes & 239 \\
\hline 5 & 83 & male & Lower & $\begin{array}{l}\text { Adenocar- } \\
\text { cinoma }\end{array}$ & TxNxM0 & Palliation & yes & 77 & 77 & yes & 133 \\
\hline 6 & 70 & male & Upper & Squamous & T4N1M0 & Palliation & no & 167 & N/A & yes & 167 \\
\hline 7 & 57 & male & Lower & $\begin{array}{l}\text { Adenocar- } \\
\text { cinoma }\end{array}$ & T3NOMO & $\begin{array}{l}\text { Initial plan to perform } \\
\text { esophagectomy but this } \\
\text { was postponed due to } \\
\text { bleeding. Had BD-stent } \\
\text { and Rx in view of reat- } \\
\text { tempting surgery but } \\
\text { only partial response- } \\
\text { palliative treatment }\end{array}$ & yes & 219 & 219 & yes & 427 \\
\hline 8 & 83 & male & Lower & $\begin{array}{l}\text { Adenocar- } \\
\text { cinoma }\end{array}$ & T3N2M0 & $\begin{array}{l}\text { Initial radical Rx but con- } \\
\text { tinued as palliative in } \\
\text { view of age and co-mor- } \\
\text { bidities }\end{array}$ & yes & 123 & 123 & yes & 31 \\
\hline 9 & 66 & male & Lower & $\begin{array}{l}\text { Adenocar- } \\
\text { cinoma }\end{array}$ & T3N2M0 & $\begin{array}{l}\text { Neoadjuvant chemother- } \\
\text { apy but suboptimal re- } \\
\text { sponse- palliative treat- } \\
\text { ment }\end{array}$ & yes & 308 & 308 & no & $\mathrm{N} / \mathrm{A}$ \\
\hline 10 & 76 & female & Middle & Squamous & T3N0M0 & Radical Rx & no & 270 & $\mathrm{~N} / \mathrm{A}$ & yes & 38 \\
\hline
\end{tabular}

BD, Biodegradable; N/A, non-applicable; Rx, Radiotherapy; SEMS, self-expanding metal stent

but tumor was considered unresectable at surgery and the procedure was abandoned.

Poor progression to surgery was either due to suboptimal response to neoadjuvant chemoradiotherapy, intolerance or development of complications. Only 1 patient was still alive at the end of the follow-up period. Overall survival following the BD stent placement ranged between 19 weeks and 98 weeks (median 34 weeks, IQR: 25-56). A 76-year-old, female patient who received radical radiotherapy developed post-radiotherapy esophageal stricture despite the placement of a BD stent prior to the therapy. She received a second BD stent a year later, but it was not effective. She required 2 dilatations in the meantime but her stricture proved to be refractory. Due to poor general health and personal preference, she had a nasogastric feeding tube placed, which was retained until her death 21 months after the initial BD stent placement. There was no documented disease recurrence until her death. Patient details, including need for SEMS and BD stent patency duration and survival, are presented in $\bullet$ Table 2 .

\section{Discussion}

$\nabla$

Although BD stents are currently licensed for benign strictures, there have been studies assessing their effect in the context of malignant strictures. In this paper, although we report our experience in both patient groups, data analysis interpretation and discussion of the results with regard to benign and malignant strictures were done separately.

Refractory esophageal strictures comprise a significant clinical challenge. As an alternative to repeated dilatations, it has been proposed that placement of a stent could lead to prolonged periods between dilatations and remodeling of the stricture, thus improving the clinical outcome. Clinical trials assessing the efficacy of FCSEMS and SEPS had suboptimal long-term outcomes. A recent meta-analysis [8] regarding the treatment efficacy of FCSEMS, SEPS and BD stents in refractory benign strictures, found an overall clinical success rate of $40.5 \%$ when all treatment modalities were considered. The differences in the success rates between the various modalities were not statistically significant. 
BD stent success rate was $32.9 \%$. No statistically significant differences were found in rates of migration (overall 28.6\%, BD-stent $15.3 \%$ ) or adverse events (AEs) (overall 20.6\%, BD-stents $21.9 \%$ ). The most common $\mathrm{AE}$ was chest pain. It is important to note that this meta-analysis detected significant heterogeneity between studies and this was more prominent in FCSEMS studies. The overall clinical success for benign strictures in this study, defined as no need for further intervention until the end of followup period, was $20 \%$. Two patients remained asymptomatic following the stent placement. Both died at 26 weeks and 9 weeks, respectively, following the $\mathrm{BD}$ stent placement, for reasons unrelated to it. Those results are similar to those previously reported, but it is important to note that none of the patients still alive at the end of the study period was asymptomatic. The serious complication rate was relatively low (5.3\%) and the migration rate was $0 \%$. No mortality attributed to stent insertion was seen. Those figures are encouraging with regard to the safety of this modality. In our cohort, chest pain was not a major problem and patients responded well to analgesia. In our experience, adequate dilatation of the stricture to at least $11 \mathrm{~mm}$ prior to BD stent insertion is important. Even though the retrospective nature of the study could potentially result in under-reporting of minor chest pain episodes, severe complications requiring prolonged hospitalization stent removal or AEs such as bleedings or perforations would have being clearly documented in the patient records.

A previous study showed a decrease in the frequency of dilatations required following BD stent placement [17]. It was not possible to assess that in our series because only 4 patients had a single BD stent and of them, only 2 required further dilatations. The remaining patients had 2 or 3 stents placed. Nevertheless, following the placement of the initial BD stent, patients experienced a median of 149.5 days ( 21 weeks) of improved symptoms, not requiring further intervention. Interestingly, this period was significantly longer than the expected lifetime of the BD stent (12 weeks). Even though the patients eventually required repeat dilatations, the intervention-free period was significantly longer compared to the previous median interval between dilatations ( 5 weeks). This gave the patients the opportunity to temporarily avoid the unpleasant experience of repeat dilatations, as pointed out in previous reports [18]. This applied also to the patients who subsequently had more than 1 additional BD stent.

Dysphagia caused by malignant strictures is a totally different problem altogether. Several factors need to be considered in the management of these patients.

Results of 2 prospective and 1 retrospective trials are now available. Krokidis et al. [16] prospectively studied 11 patients with malignant strictures. Early complication rates were significant (27.2\%) and 2 out of 11 patients died due to complications related to tracheoesophageal fistula formation. Only 3 patients had a patent stent at the end of the follow-up period and were supposed to complete neoadjuvant chemotherapy prior to esophagectomy. Griffiths et al. [19] included 16 patients with malignant strictures. Only 1 was waiting for surgery, 4 months after BD stent placement. There were 3 patients that progressed to attempted resection, but their tumors were found to be unresectable. The rest showed disease progression or were deemed unfit for surgery. Eight required SEMS insertion and 2 required nasogastric tube placement. Similar low rates of progression to surgery in the neoadjuvant setting have been reported previously for FCSEMS [20]. Finally, Van der Berg et al. [21] prospectively studied 10 patients with malignant esophageal strictures who received BD stents while undergoing neoadjuvant chemoradiotherapy.
They reported 30-day morbidity and overall AE rates of $60 \%$ and $70 \%$, respectively. Most of those AEs were related to retrosternal pain, sometimes lasting for more than 10 days, while 1 case of stent obstruction due to necrotic tissue was also reported. No stent migration was noted. At the end of follow-up, 6 of 10 patients underwent esophagectomy. Despite this relatively positive outcome, 9 of 10 patients experienced weight loss at the end of follow-up and the authors raised concerns that the pain might have led to reduced eating.

In line with Griffiths et al. [19], we also documented a disappointingly low rate of progression to surgery $(0 \%)$. This was a selective group of patients in the context of a retrospective study who were considered fit for radical therapies but they were borderline with regard to their potential for curative interventions. Half of our patients eventually needed a SEMS and only 1 patient receiving radiotherapy seemed to be disease-free at the time of her death. Nevertheless, she had developed a refractory postradiotherapy stricture, despite placement of a BD stent. On the positive side, BD stents remained patent not needing further intervention for a median of 204 days, significantly more than the expected lifespan of the stent itself.

In accordance with Van den Berg et al. [21], post-insertion chest pain was the most common complication in our series, affecting 3 out of 10 patients. Post-procedural pain is most likely related to the increased axial force [22], the relatively large diameter of these stents, and the need for dilatation prior to stent deployment. However, in contrast to the aforementioned study, none of our patients experienced significant pain requiring analgesia for more than 48 hours. This may be related to the fact that, with a single exception, all our patients had dilatation to $10 \mathrm{~mm}$ to $11 \mathrm{~mm}$. In contrast, patients in the Nan den Berg et al. study only received dilatation if the stricture was not passable with the pediatric scope, and when dilated, this was done to $10 \mathrm{~mm}$ at most. Furthermore, differences regarding the severity of baseline dysphagia and/or tumor characteristics may have also contributed to this discrepancy. We did not document any case of stent migration in the malignant group of this study and there was no 30-day mortality or any severe procedure-related complications, in line with Van den Berg et al. Tissue ingrowth was noted in 2 patients and in 1 patient was severe enough to cause food bolus obstruction. Endoscopic intervention in the form of APC treatment and subsequent SEMS placement were required. Generally the tissue reaction was mild and actually helped anchor the stent and prevent migration.

This study has certain limitations. First, it is retrospective and lacks a control group. As such, there is unavoidable selection bias. Stent insertion was determined on an individual basis not using the Kochman criteria [23]but rather, using a realistic approach, taking into consideration logistic parameters and patient preference. Patients with benign refractory esophageal strictures were generally those who had multiple failed dilatations and were therefore the most difficult to treat in any case. We did not evaluate pre- and post-intervention symptom scores or qualityof-life metrics. Nevertheless, despite this not being a comparative study, the number of patients was comparable to previous studies, while the follow-up period was probably the longest reported to date, for both benign and malignant indications. 


\section{Conclusions}

\section{$\nabla$}

Application of BD stents is relatively safe and the main complication is retrosternal pain, which tends to be moderate. Biodegradable stents in benign refractory esophageal strictures seem to provide a dilatation-free interval for patients which can be significantly longer than the expected life expectancy of the stent. However, in the long term, the vast majority of patients require repeat interventions. The role of repeated BD stent placements should be assessed prospectively and compared to repeat dilatations using a formal predefined study protocol.

Regarding malignant strictures, although the period of stent patency was similar to that for benign strictures, patient outcomes were not encouraging. Similarly discouraging results have been reported for other stenting options in the neoadjuvant setting [13]. Therefore, although BD stents may have a role in patients with esophageal cancer to improve oral intake without the need for nasogastric feeding during oncological therapy, at present, there are no data to support their use in that population to improve outcomes. Further studies are needed to prospectively assess the use of BD stents in esophageal malignancy.

\section{Competing interests: None}

\section{Acknowledgement \\ $\nabla$}

we would like to acknowledge Mrs. Sam Bow, ERCP coordinator for her invaluable help in the collection of data.

\section{References}

1 Parasa S, Sharma P. Complications of gastro-oesophageal reflux disease. Best Pract Res Clin Gastroenterol 2013; 27: 433-442

2 Pregun I, Hritz I, Tulassay $Z$ et al. Peptic esophageal stricture: medical treatment. Dig Dis 2009; 27: 31 - 37

3 Pereira-Lima JC, Ramires RP, Zamin I et al. Endoscopic dilation of benign esophageal strictures: report on 1043 procedures. Am J Gastroenterol 1999; 94: 1497-1501

4 Ramage JI, Rumalla A, Baron TH et al. A prospective, randomized, double-blind, placebo-controlled trial of endoscopic steroid injection therapy for recalcitrant esophageal peptic strictures. Am J Gastroenterol 2005; 100: 2419-2425

$5 \mathrm{Kim} J H$, Shin JH, Song H-Y. Benign strictures of the esophagus and gastric outlet: interventional management. Korean J Radiol11: 497-506

6 Eloubeidi MA, Lopes TL. Novel removable internally fully covered selfexpanding metal esophageal stent: feasibility, technique of removal, and tissue response in humans. Am J Gastroenterol 2009; 104: 1374 1381
7 Dan DT, Gannavarapu B, Lee JG et al. Removable esophageal stents have poor efficacy for the treatment of refractory benign esophageal strictures (RBES). Dis Esophagus 2014; 27: $511-517$

8 Fuccio L, Hassan C, Frazzoni L et al. Clinical outcomes following stent placement in refractory benign esophageal stricture: a systematic review and meta-analysis. Endoscopy 2016; 48: 141 -148

9 Langer FB, Schoppmann SF, Prager G et al. Temporary placement of selfexpanding oesophageal stents as bridging for neo-adjuvant therapy. Ann Surg Oncol 2010; 17: 470-475

10 Abu Dayyeh BK, Vandamme JJ, Miller RC et al. Esophageal self-expandable stent material and mesh grid density are the major determining factors of external beam radiation dose perturbation: results from a phantom model. Endoscopy 2013; 45: $42-47$

11 Francis SR, Anker CJ, Wang B et al. Self-expanding stent effects on radiation dosimetry in esophageal cancer. J Appl Clin Med Phys 2013; 14: 4218

12 Li XA, Chibani O, Greenwald B et al. Radiotherapy dose perturbation of metallic esophageal stents. Int J Radiat Oncol Biol Phys 2002; 54: $1276-1285$

13 Jones CM, Griffiths EA. Should oesophageal stents be used before neoadjuvant therapy to treat dysphagia in patients awaiting oesophagectomy? Best evidence topic (BET) Int J Surg 2014; 12: 1172 - 1180

14 Fry SW, Fleischer DE. Management of a refractory benign esophageal stricture with a new biodegradable stent. Gastrointest Endosc 1997; 45: $179-182$

15 Stivaros SM, Williams LR, Senger $C$ et al. Woven polydioxanone biodegradable stents: a new treatment option for benign and malignant oesophageal strictures. Eur Radiol 2010; 20: 1069-1072

16 Krokidis M, Burke C, Spiliopoulos S et al. The use of biodegradable stents in malignant oesophageal strictures for the treatment of dysphagia before neoadjuvant treatment or radical radiotherapy: a feasibility study. Cardiovasc Intervent Radiol 2013; 36: 1047-1054

17 Repici A, Vleggaar FP, Hassan C et al. Efficacy and safety of biodegradable stents for refractory benign esophageal strictures: the BEST (Biodegradable Esophageal Stent) study. Gastrointest Endosc 2010; 72: 927-934

18 Hirdes MMC, Siersema PD, van Boeckel PGA et al. Single and sequential biodegradable stent placement for refractory benign esophageal strictures: a prospective follow-up study. Endoscopy 2012; 44: 649-654

19 Griffiths EA, Gregory CJ, Pursnani KG et al. The use of biodegradable (SX-ELLA) oesophageal stents to treat dysphagia due to benign and malignant oesophageal disease. Surg Endosc 2012; 26: 2367-2375

20 Lopes TL, Eloubeidi MA. A pilot study of fully covered self-expandable metal stents prior to neoadjuvant therapy for locally advanced esophageal cancer. Dis Esophagus 2010; 23: 309-315

21 van den Berg MW, Walter D, de Vries EMG et al. Biodegradable stent placement before neoadjuvant chemoradiotherapy as a bridge to surgery in patients with locally advanced esophageal cancer. Gastrointest Endosc 2014; 80: 908 - 913

22 Hirdes MMC, Vleggaar FP, de Beule $M$ et al. In vitro evaluation of the radial and axial force of self-expanding esophageal stents. Endoscopy 2013; 45: 997-1005

23 Kochman ML, McClave SA, Boyce HW. The refractory and the recurrent esophageal stricture: a definition. Gastrointest Endosc 2005; 62: 474475 